\title{
Impactos da Tecnologia na Gestão de Pessoas - um Estudo de Caso
}

\author{
AndréOfenhejm Mascarenhas \\ Flavio Carvalho de Vasconcelos \\ Isabella F. G. de Vasconcelos
}

\section{Resumo}

Pesquisas sobre gestão de pessoas no Brasil indicam uma fase de transição pela qual a área de RH passa atualmente, de uma atuação predominantemente operacional para modelos mais estratégicos de gestão de pessoas. Neste contexto, a implementação de tecnologias, como a informatização por meio de aplicações de RH auto-atendimento, vem sendo considerada uma maneira de viabilizar novos arranjos organizacionais da gestão de pessoas. Este artigo tem como objetivo discutir os impactos da tecnologia da informação e o seu papel estratégico no contexto de transição da gestão de pessoas. Por meio de um estudo de caso, mostramos que a tecnologia pode ser ferramenta útil na consolidação de novas estratégias de gestão de pessoas na medida em que interaja com outros aspectos organizacionais para a emergência de novo sistema social. Podemos verificar que a informatização viabilizou a emergência do modelo político de gestão de pessoas, que é condição que viabiliza formas orgânicas de organização, nas quais a informação é melhor aproveitada para a aprendizagem organizacional.

Palavras-chave: gestão de pessoas; tecnologia da informação; sistemas de auto-atendimento; aprendizagem organizacional.

\section{Abstract}

Research on the current state of human resource management in Brazil indicates an important transition phase facing HR departments today: an evolution from operational to more strategic models of people management. In this context, information technology, such as self-service systems, has been considered a way of building new models of human resource management. This article discusses the impacts of IT and its strategic role in the transition context of HR management. Through a case study, we will show that technology can be a useful tool in reinforcing new strategies of HR management when it interacts with other organizational elements to the emergence of a new social system. We can verify that technology allowed the emergence of the political model of human resource management. This HRM model is a prerequisite to organic organizational models where information is used for learning.

Key words: human resource management; information technology; self-service systems; organizational learning. 


\section{Introdução - a Transição da Área de RH no Brasil e a TECNOLOgia de INFORMAÇÃo}

Pesquisas sobre o contexto da gestão de pessoas no Brasil indicam importante fase de transição pela qual a área de RH passa atualmente, de uma atuação predominantemente operacional para modelos mais orgânicos de gestão de pessoas (FISCHER, 1998; FISCHER, 2002; FISCHER; ALBUQUERQUE, 2001; LACOMBE; TONELLI, 2000). Lacombe e Tonelli (2000), ao sugerirem um descompasso significativo entre a identificação de tendências pelos diversos formadores de opinião na área de RH e a prática efetiva de gestão de pessoas nas empresas brasileiras, indicam claramente esta fase de transição. $\mathrm{O}$ trabalho de Fischer e Albuquerque (2001), por meio de extensa pesquisa realizada na área de RH no Brasil, confirma que os formadores de opinião em gestão de pessoas no Brasil adotam novos discursos que defendem a politização dos indivíduos nas organizações.

Neste período de transição, estes autores mostram ainda que a aprendizagem organizacional é variável progressivamente defendida e valorizada pelos profissionais nos novos modelos de gestão de pessoas, que emergem no Brasil, chamados genericamente de ARH como vantagem competitiva (FISCHER, 1998). Neste contexto, a implementação da tecnologia da informação vem sendo considerada uma maneira de viabilizar novos arranjos organizacionais da gestão de pessoas. A implementação crescente dos chamados sistemas de RH autoatendimento é um indicativo desta tendência. Estes sistemas possibilitam o amplo acesso do funcionário a informações e funções personalizadas e relevantes para a administração de seu relacionamento com a organização (MASCARENHAS, 2003).

Este artigo tem como objetivo discutir os impactos da tecnologia da informação neste contexto de transição da gestão de pessoas. Por meio de um estudo de caso, discutiremos o papel da tecnologia na consolidação de novos modelos de gestão de pessoas. A primeira parte do artigo discute o potencial das atuais tecnologias de informação para viabilizar novos arranjos organizacionais caracterizados pela aprendizagem. A partir da constatação de que a implementação da tecnologia é parte de um processo de amplas mudanças sociotécnicas, discutimos na terceira parte do artigo o modelo político de gestão de pessoas, apropriado aos contextos organizacionais orgânicos, caracterizados pela aprendizagem. Após definirmos os sistemas de RH auto-atendimento e discutirmos a metodologia de pesquisa, apresentamos o caso de uma organização que utilizou 
a tecnologia para consolidar um novo modelo de gestão de pessoas, com base na politização dos indivíduos e na aprendizagem. A última parte do artigo problematiza o uso da tecnologia para a consolidação de novos modelos de gestão de pessoas, ao apontar desafios futuros neste processo.

\section{Tecnologia da Informação, Modelos Organizacionais e Aprendizagem}

Há algum tempo, a idéia de que o modelo organizacional mecânico, como definido por Burns e Stalker (2001), não satisfaz as necessidades de muitas organizações contemporâneas, é bastante difundida. Ao enfatizar a necessidade de se transformar as organizações, para que fiquem mais flexíveis e dinâmicas, o discurso gerencial defende a emergência de organizações orgânicas. Temas como novos modelos de gestão de pessoas, fortalecimento de equipes multifuncionais de trabalho, delegação de responsabilidades e a aprendizagem organizacional emergem desta discussão. Castells (1999) mostra que este fenômeno acontece em contexto de transição entre o modelo industrial e pós-industrial.

Muitos autores defendem que as potencialidades das novas aplicações de tecnologia da informação (TI) podem viabilizar a emergência de novos modelos organizacionais, caracterizados pela dinâmica da aprendizagem. Zuboff (1988 e 1994), por exemplo, discute a dualidade que caracteriza a tecnologia e a relaciona a dois modelos organizacionais e a dois tipos de aprendizagem. A autora destaca que, em primeiro lugar, a tecnologia pode ser utilizada para automatizar operações. O objetivo é substituir o esforço e a qualificação humanos por uma tecnologia que permita que os mesmos processos sejam executados, a um custo menor, com mais controle e continuidade. A robotização de fábricas, substituindo a mão de obra humana com mais eficiência, é um exemplo desta função da tecnologia (ZUBOFF, 1988, 1994). Esta função está relacionada às organizações mecânicas e permite que se melhorem continuamente os atuais processos. Trata-se da aprendizagem de circuito simples, que se baseia na detecção do erro e na sua correção, preservandose, no entanto, os pressupostos do sistema operacional, ou seja, os valores de base que inspiram o funcionamento do sistema. Em se tratando de processos de produção ou administrativos, pode-se dizer que se trata da melhoria contínua, em que se aprimora a eficiência de um dado processo, aperfeiçoando-se a sua prática e a sua execução até um nível ótimo, sem questionar-se, no entanto, os valores de base do sistema ou as suas etapas de funcionamento (ARGYRIS, 1992; BURNS; STALKER, 2001). 
Segundo Zuboff (1988; 1994), a tecnologia tem ainda outro potencial: a informatização. Neste caso, vai-se além da mera automação, gera-se novo fluxo de informações que aperfeiçoa o próprio sistema e permite o questionamento dos métodos atuais e a reconfiguração do trabalho. A informatização está relacionada às organizações orgânicas e permite o questionamento e reconfiguração dos atuais processos. Trata-se da aprendizagem de circuito duplo, base da inovação, que implica um processo de percepção e exploração das possibilidades do ambiente. Em primeiro lugar o indivíduo tem acesso a novas informações. Em segundo lugar compara as informações obtidas com as normas de funcionamento de um dado sistema ou processo, ao que se segue o questionamento da pertinência das normas de funcionamento do sistema e a iniciação de ações corretivas apropriadas, que podem envolver a mudança das práticas, valores e pressupostos do sistema ou processo antigo. No que se refere aos processos produtivos e gerenciais, propõe-se questionar habitualmente as bases de seu funcionamento, a partir de novas informações obtidas, redesenhando-se o processo ou a organização, desde que necessário (ARGYRIS, 1992; BURNS; STALKER, 2001).

Entretanto autores que partem da análise da organização como sistema natural consideram que a implementação da TI pura e simplesmente não garante a plena concretização de suas potencialidades (BERKLEY; NOHRIA, 1994; KLING, 1996; MORTON, 1996; ORLIKOWSKI, 1996; SCOTT, 1992; WALTON, 1994; ZUBOFF, 1988). Pode-se dizer, por exemplo que, a partir da implementação da tecnologia, a aprendizagem não é automática e envolve freqüentemente contradições. De acordo com a teoria perspectiva da ação, os indivíduos agem de acordo com suas crenças e pressupostos, isto é, valores que embasam sua ação e oferecem padrões de interpretação da realidade. Uma parte destes padrões pode ser modificada, levando à mudança na ação e no comportamento dos indivíduos, pressuposto da aprendizagem; no entanto rotinas defensivas impedem a adoção efetiva de práticas que se oponham às crenças básicas dos indivíduos. Os indivíduos não adotam comportamentos ou não tomam conhecimento de informações que lhes produzam desconforto e angústia. Desta forma, existe uma defasagem freqüente entre a teoria adotada, o que se diz que se faz, e a teoria efetivamente praticada, isto é, como realmente se age: os indivíduos podem dizer que incorporam certo tipo de comportamento, eles acreditam nisso; mas um bloqueio cognitivo os impede de adotar efetivamente estes comportamentos (ARGYRIS; SCHÖN, 1978). Desta maneira, os autores que partem da análise da organização como sistema natural discutem a necessidade de se tratar o ambiente social, em que a tecnologia é implementada, partindo da premissa de que a TI deve ser entendida como parte de um amplo sistema sociotécnico.

Neste sentido, viabilizar a emergência de novos modelos organizacionais, 
caracterizados pela aprendizagem de circuito duplo, requer intervenções em amplos contextos sociotécnicos, o que implica mudanças em padrões de comportamentos já consolidados. Pode-se dizer que uma destas mudanças é a emergência do Modelo Político de Gestão de Pessoas, descrito a seguir. Em organizações orgânicas marcadas pelo constante questionamento das próprias formas de comportamento e pela mudança, faz-se necessário um perfil de indivíduo mais autônomo e questionador, próprio deste modelo de gestão de pessoas (BRABET, 1993).

\section{O Modelo Político de Gestão de Pessoas}

Pode-se conceituar modelo de gestão de pessoas como a maneira de uma organização se estruturar para gerenciar e orientar o comportamento humano no ambiente de trabalho. Um modelo de gestão de pessoas é formado por todos os elementos que interferem de alguma maneira no comportamento dos indivíduos no contexto organizacional. Este conceito não se restringe ao caráter instrumental da gestão de pessoas, mas diz respeito às diferentes lógicas que influenciam o comportamento na organização. O modelo de gestão de pessoas, desta maneira, sistematiza componentes políticos, ideológicos, sociais e comportamentais que orientam a ação e a decisão no contexto organizacional (MASCARENHAS, 2003; FISCHER, 1998). Segundo Fischer (2002), o que diferencia um modelo do outro são as características dos seus elementos constituintes, como princípios, processos, estruturas e políticas de RH.

Podemos associar o modelo político de gestão de pessoas às organizações orgânicas, e diferenciá-lo do modelo instrumental de gestão de pessoas, associado às organizações mecânicas. Segundo o modelo instrumental de gestão de pessoas, a empresa é considerada um instrumento racional de produção e sua estratégia é definida por seus diretores em função das pressões do mercado. A administração de recursos humanos tem a função de implantar esta estratégia, buscando a maximização do resultado econômico e o melhor desempenho dos empregados. Este modelo é baseado no argumento de que a sociabilidade harmônica gera a eficiência econômica e vice-versa. Isso significa considerar que o conflito é disfuncional e prejudicial ao sistema social. Procura-se evitar os conflitos ou resolvê-los rapidamente, pois se considera que um ambiente homogêneo, com alto grau de conformismo por parte dos atores sociais, favorece a produtividade na empresa. Evitam-se debates desnecessários e as decisões são tomadas unilateralmente pelos dirigentes. A diversidade cultural e de opiniões é considerada um problema a ser reprimido. 
Já o modelo político de gestão de pessoas caracteriza-se pela incorporação da idéia de conflito tendo em vista as várias lógicas de ator e critérios de ação válidos e os diferentes interesses dos atores organizacionais, segundo as idéias de Simon sobre racionalidade limitada (SIMON, 1955). Um bom gerente, segundo este modelo, é um árbitro que tem como objetivo obter esta coesão integrando os interesses particulares dos diferentes grupos de atores sociais, visando a obter soluções negociadas junto à direção da empresa, ou pactos políticos (BRABET, 1993; VASCONCELOS; VASCONCELOS, 2002). As políticas de RH da empresa são vistas como mutantes e contingentes, sendo soluções temporárias e características de situações específicas a partir de um diagnóstico organizacional. Apesar disso, os profissionais da área buscam organizar a gestão de pessoas como um modelo ideal a ser concretizado a longo prazo, envolvendo o desenvolvimento qualitativo da mão-de-obra, a autonomia e a democratização das relações.

O modelo político visa a oferecer possibilidades de debate e negociação na organização, a fim de promover o contraditório em busca de soluções mais completas, em torno das quais se obtenham os consensos. Busca-se vislumbrar as diversas opções de ação antes de decidir, tendo-se como pressuposto que esta é forma mais inteligente de se lidar com a realidade complexa. Este modelo incentiva a diversidade cultural, já que permite a verificação de várias lógicas de ação diante de uma questão organizacional. Pode-se dizer que este modelo favorece a emancipação dos indivíduos e o seu desenvolvimento político e cognitivo na medida em que tem como pressuposto a inserção ativa dos indivíduos na dinâmica organizacional. Outras características deste modelo vêm explicitadas em seguida.

. Eficiência econômica negociada, não correspondendo necessariamente à eficiência social de curto prazo: aceitam-se conflitos, buscando-se negociá-los politicamente.

- Avaliação dos resultados feita dentro dos grupos organizacionais envolvidos nos processos de decisão.

. Empresa construída socialmente por meio da ação política dos diversos grupos organizacionais.

- Maior qualificação e politização dos grupos organizacionais para a interação social.

- Decisões racionais e éticas, referindo-se à resolução de conflitos, à obtenção do consenso e às questões de poder. 
. Indivíduos vistos como atores políticos válidos, com potencial de desenvolvimento positivo, buscando concretizar ativamente seus próprios interesses.

\section{A Informatização da Gestão de Pessoas: Sistemas de RH Auto-atendimento}

A TI avançada, amplamente implementada em todas as áreas das empresas, somente nos últimos anos começa a ser considerada uma ferramenta para alavancar o processo de mudança da gestão de pessoas, como discutem diversos autores (ALBERTIN, 1998; LAWLER III; MOHRMAN, 1995; ULRICH, 2000). Uma das novas aplicações de TI, cujo potencial para a informatização pode transformar os processos de gestão de pessoas, são sistemas genericamente conhecidos por RH auto atendimento e, segundo McCormick (1998), são provavelmente a mudança mais significativa em termos de serviços de RH nos últimos anos.

O conceito de sistema de RH auto atendimento, segundo Teuke (2001), parte de uma zona de interação, mais comum atualmente, para a sua integração com mais três, em desenvolvimento nas organizações líderes. A primeira zona conecta o funcionário à empresa, onde são disponibilizados os serviços tradicionais da área de RH, como administração de férias e comprovantes de pagamento. Tecnologias Web, entre outras, são utilizadas em ritmo crescente para fornecer aos funcionários o acesso direto a informações corporativas e administração de serviços de recursos humanos, permitindo a realização de transações eletrônicas que costumavam ser realizadas por meio do pessoal administrativo.

A segunda zona conectaria então os funcionários entre si, facilitando a colaboração e a democratização do conhecimento. Estão aí as ferramentas de administração do conhecimento. A terceira zona conectaria o funcionário às tarefas. Seriam disponibilizadas aí as ferramentas e aplicações específicas para determinada tarefa ou grupo de tarefas. A quarta zona conectaria o funcionário a aspectos de sua vida fora da empresa. Nesta zona, o funcionário poderia também acessar informações e administrar eventos que não ocorrem nos limites da empresa. O estudo de caso apresentado tratará de discutir os benefícios da informatização da gestão de pessoas por meio de um sistema de RH auto atendimento. 


\section{Metodologia de Pesquisa}

Esta pesquisa foi baseada no método do estudo de caso, definido por Yin (2001, p. 32) como "um questionamento empírico que investiga um fenômeno contemporâneo com seus contextos de vida real, quando as fronteiras entre o fenômeno e o contexto não são claramente evidentes, e nos quais múltiplas fontes de evidência são usadas”.

Empreendeu-se um estudo de caso único em uma organização que se encontrava em fase avançada no processo de implementação de um sistema de RH auto-atendimento. Esse critério foi importante, porque, apenas a partir destas fases de implementação, o caso revela o seu potencial de análise. Foi utilizado o referencial de Letart (1998) para a definição das fases mais apropriadas para efeitos desta análise. Analisar um caso único foi a estratégia adotada, por se tratar de fenômeno recente no Brasil. A quase totalidade das empresas brasileiras, com projetos em andamento, ainda não passou da segunda fase de implantação dos sistemas RH auto-atendimento, quando transações simples são feitas por meio digital, não sendo portanto ideais para os fins desta análise (LETART, 1998).

O estudo de caso, apresentado neste projeto, é do tipo incorporado, isto é, a investigação foi dividida em algumas subunidades de análise, ao invés de um estudo que examinasse apenas a natureza global do fenômeno (YIN, 2001). As unidades de análise incorporadas serão: (1) as percepções dos executivos da área de RH; (2) as percepções dos demais funcionários da área de RH; e (3) as percepções dos clientes da área de RH, isto é, os demais funcionários da empresa, em diversos níveis hierárquicos. Em relação a cada unidade de análise, foram utilizados convenientemente os seguintes métodos de levantamento de dados: (1) entrevistas com pessoas relevantes; (2) análise de documentos; e (3) observação de processos. As 18 entrevistas foram semi-estruturadas, gravadas e duraram em médias 2 horas. Os documentos analisados incluíram comunicações internas, projetos, apresentações executivas e material de treinamento. Além disso, foram observados diversos processos de gestão de pessoas, informatizados e nãoinformatizados, no que diz respeito aos padrões de comportamento e interação dos indivíduos.

Segundo Yin (2001), o modelo de estudo de caso deve ser passível de julgamento de sua qualidade. Neste estudo, foram analisadas evidências provenientes das três unidades de análise, permitindo que se pudesse compreender o fenômeno estudado sob diversos ângulos, além das diversas fontes de evidências a serem utilizadas, que se reforçam mutuamente, evitando a utilização de informações tendenciosas ou equivocadas. Além destes fatores, o relatório preliminar de estudo de caso foi 
lido e discutido por 3 informantes críticos identificados. Cada informante crítico pertencia a uma das unidades de análise, como descritas anteriormente, e sua atuação limitou-se a rever o relatório de pesquisa, a fim de apontar incongruências e inconsistências, que foram então retrabalhadas. A tática para garantir a confiabilidade deste estudo foi a utilização do protocolo de estudo de caso e a documentação do caso. O estudo de caso será utilizado para a generalização analítica, por meio da qual uma teoria previamente desenvolvida como modelo é utilizada para a comparação com os resultados empíricos do caso (YIN, 2001).

No caso apresentado a seguir, procuramos reconstituir as reações dos atores organizacionais à informatização dos serviços de RH da organização como forma de construir um entendimento sobre uma nova realidade organizacional: como estes concebiam estes sistemas, se o utilizavam ou não; se havia fenômenos de resistência à mudança; se estes sistemas estimulavam a aprendizagem de circuito duplo (ARGYRIS, 1992); se havia contradições entre o discurso e a ação na organização e os seus efeitos. A investigação em campo tratou de mapear a dinâmica social dos grupos como forma de verificar a sua relação com um dos modelos de gestão de pessoas discutidos, o modelo instrumental ou o político.

A organização industrial DaimlerChrysler unidade Wörth, Alemanha, pareceunos um caso adequado. Apesar do contexto cultural particular no qual se encontra inserida, a organização tem práticas informatizadas consolidadas de gestão de pessoas, o que permitiu análises mais completas das novas estratégias de gestão de pessoas na transição da área de RH, conceito que também é relevante naquele contexto. Além disso, a organização tem amplo histórico de utilização da tecnologia da informação como ferramenta de competitividade em seus processos, e não como negócio central, o que permitiu eliminarmos alguns possíveis vieses na escolha da organização ideal. A empresa se mostrou prontamente disposta a dar o suporte necessário às atividades de pesquisa. Destacamos que o pesquisador não possui nenhum vínculo com a organização e que recebeu auxílio desta para deslocamento e hospedagem. Este estudo de caso foi realizado nos meses de setembro e outubro de 2002.

\section{Estudo de Caso: a Informatização da Gestão de Pessoas na DaimlerChrysler, Wörth, Alemanha}

A unidade da DaimlerChrysler em Wörth, na Alemanha, produz em média 82.000 unidades de veículos comerciais por ano. Conta com uma força de trabalho de aproximadamente 9.000 funcionários, sendo 450 em níveis gerenciais. Sua área de RH emprega aproximadamente 150 funcionários. 


\section{A Área de RH e o Projeto RYB.com}

Tradicionalmente, a área de RH pode ser descrita como as equipes que desempenham atividades relacionadas a processos de gestão de pessoas. A área de RH na organização sofria dos males normalmente atribuídos a esse departamento. Era tradicionalmente reconhecida como área operacional, envolvida em processos administrativos burocráticos, que não agregavam qualidade ao relacionamento entre chefes e subordinados e aos processos internos. Uma mudança na alta gerência desencadeou, entretanto, uma reação nesse estágio das coisas, ao canalizar o desejo de transformação da área a um projeto estratégico concreto, que abrangia profundas alterações na sua organização social, além da implementação da TI como nova maneira de organizar os processos de gestão de RH.

O projeto reinvent your business.com (RYB.com), implementado em um período de 2 anos, representou ampla iniciativa de transformação da área de RH empreendida na organização. Esse projeto foi grande intervenção em uma situação social há tempos intocada na área e envolvia uma série de mudanças na organização da gestão de pessoas. A estratégia traçada pela área tinha como premissa a constatação de que os processos de gestão de pessoas deveriam ser de responsabilidade de todas as áreas, já que eram inerentes ao relacionamento entre chefes e subordinados. A atuação do RH, dessa maneira, não devia ser caracterizada pela centralização dos processos, como era até então, já que isso levava ao empobrecimento do relacionamento.

Partindo-se desta premissa, a nova filosofia da área centrava-se na necessidade de se atender à organização da melhor forma possível, agregando qualidade aos processos relativos à gestão de pessoas. Para isso a área de RH deveria deixar de concentrar a execução de todos esses processos, para atuar de maneira mais consultiva, influenciando, por meio do conhecimento e do know-how, o desenvolvimento das questões humanas na organização. Um analista resumiu assim os novos padrões de atuação da área:

"A filosofia era a de que o RH não deveria ser importante somente por estar lá, mas sim por agregar realmente qualidade no relacionamento entre gestores e funcionários, e empresa. Desta maneira, o RH deveria atuar não como um centralizador de operações relativas à gestão de pessoas, mas sim como um facilitador. Estes processos são inerentes ao cotidiano dos gestores, e não deveriam ser de inteira responsabilidade da área de RH. Dar mais poder ao cliente e atuar como um suporte especializado foi a forma de possibilitar ao RH uma atuação que agregasse mais qualidade à gestão de pessoas”. 


\section{Projeto RYB.com e Mudanças Organizacionais}

A implementação da nova filosofia de gestão de pessoas implicava amplas e profundas transformações na área de RH como, por exemplo, o modelo de hierarquia, o perfil dos líderes de equipe, os padrões de comunicação entre as equipes, o lay-out da área, a organização dos processos, as responsabilidades e competências dos analistas, os padrões de interação com as áreas clientes etc. Discutiremos algumas dessas mudanças, relacionadas aos processos de gestão de pessoas.

Até 1999, a diretoria de RH da unidade de Wörth era estruturada segundo um princípio de multifuncionalidade dos funcionários. Todos os processos de gestão de pessoas eram desempenhados por quatro grandes equipes multifuncionais, com quatro lideranças diferentes. Essas equipes interagiam, cada uma com áreas diferentes da fábrica, e tinham a responsabilidade de atender e responder a todo tipo de demanda na organização. Estas equipes tinham funções operacionais, relacionadas à operação cotidiana dos diversos sistemas de gestão de pessoas, e responsabilidades mais estratégicas, como o atendimento de demandas específicas nas áreas. Para esta última função, estes quatro Times de Suporte de Pessoas contavam ainda com o auxílio de algumas outras equipes especialistas em determinados processos, políticas e serviços. Até então, a atuação das equipes multifuncionais era caracterizada pela falta de padronização no tratamento aos clientes e, muitas vezes, pela falta de conhecimentos relacionados à administração de determinados assuntos e processos.

As mudanças empreendidas levaram à implementação do conceito de especialização na atuação dos analistas de RH. As quatro grandes equipes multifuncionais foram reestruturadas, o que resultou na sua divisão em dois tipos de equipes. O primeiro tipo são os consultores multifuncionais, cuja atuação pode ser classificada como a linha de frente da área. Esta equipe é responsável pelo contato inicial com o funcionário ou área cliente na busca de solução das suas demandas. Eles fazem parte de uma nova estrutura chamada PDC (Personaldienstleistungcenter, ou central de serviços de RH), sob uma liderança unificada. O PDC opera uma central telefônica, como opção para o atendimento inicial das demandas de gestão de pessoas da organização.

O número de membros do PDC é menor que o número total de membros das quatro antigas equipes multifuncionais. $\mathrm{O}$ restante dos funcionários foi alocado nas chamadas equipes especialistas. Este segundo tipo de equipe é responsável pelo desenvolvimento de processos específicos, como treinamento e desenvolvimento de pessoas, desenvolvimento e aplicação de política de salários, políticas de empregabilidade etc., além do atendimento a demandas específicas 
da organização, relacionadas a estes processos, aquelas que não podem ser resolvidas diretamente pelos analistas do PDC. A reestruturação das quatro equipes multifuncionais levou a um aumento no número de equipes especialistas, que já existiam na estrutura anterior, permitindo maior especialização em suas responsabilidades.

Entretanto a reestruturação das quatro antigas equipes multifuncionais foi além, na medida em que grande parte de suas antigas responsabilidades operacionais desapareceu. Por meio da descentralização operacional, por meio do uso intensivo de tecnologia da informação, as responsabilidades pelas funções relacionadas à operação diária dos diversos sistemas de gestão de pessoas foram redistribuídas. Antes das mudanças, a maioria destes procedimentos era realizada pelas quatro antigas equipes multifuncionais de RH. Os procedimentos relacionados à operação diária dos processos de gestão de pessoas envolviam a interação intensiva das antigas equipes de RH com os gestores, já que aqueles centralizavam a coleta e o tratamento dos dados. Isso implicava em fluxos não-racionalizados de circulação de dados.

Ao planejar a implementação do sistema de RH auto-atendimento, a área de RH se viu diante da oportunidade de reorganizar os seus processos de administração de forma que pudesse viabilizar novos fluxos de atividades, redistribuindo as responsabilidades pelas questões relacionadas à gestão de pessoas. O sistema de RH auto-atendimento de Wörth tinha como interface com o usuário um grande portal. Esse portal é acessado por meio da Intranet corporativa, à qual todos os funcionários de escritório têm acesso, por meio de seus terminais de trabalho, além dos funcionários da produção, que têm acesso por meio de terminais interativos espalhados pela fábrica. O portal Personal, como é chamado, é ainda dividido em diversas zonas, acessadas por públicos diferentes. Mostramos, abaixo, parte dos processos aos quais o sistema dá acesso indiscriminado:

. Cadastro para recrutamento interno. O funcionário disponibiliza e atualiza, de acordo com seus interesses, seu currículo pessoal e uma ficha de intenções na carreira profissional. Esses dados são utilizados no processo de recrutamento interno e gerenciamento de carreira.

. Banco de Horas. O funcionário tem acesso a informações consolidadas sobre seu saldo de horas.

. Programa de melhoria contínua. O funcionário acompanha o status de sua sugestão ao programa de melhorias organizacionais. Trata-se de um programa permanente de sugestões. 
Além destes serviços acessados indiscriminadamente, o Portal Personal disponibiliza aos gestores de equipes as seguintes ferramentas para a gestão de pessoas sob sua responsabilidade, entre outras:

- Informações sobre treinamento na área. O gestor tem um panorama dos processos de treinamento em andamento na área, os envolvidos e os seus custos. Esta função torna possível a administração da verba de treinamento e o acompanhamento do desenvolvimento profissional da área como um todo.

- Informações sobre chefes subordinados. Os gestores têm acesso a várias informações sobre chefes subordinados, como nível salarial e tempo de casa, em um esquema comparativo à organização.

- Informações salariais sobre subordinados. Os gestores acessam toda a situação salarial de sua equipe, até mesmo com os parâmetros da última avaliação de resultados, que influencia o nível de salário variável. Esta ferramenta permite comparações, levando-se em conta diversos critérios.

- Avaliação de desempenho. O gestor tem acesso aos formulários eletrônicos que devem ser regularmente preenchidos, segundo os critérios da empresa, para se avaliar o desempenho de seus funcionários. Os resultados dessa avaliação servem de parâmetro em diversos outros processos.

- Planejamento de pessoas. O gestor tem acesso a uma ferramenta eletrônica que possibilita o planejamento de funcionários de sua equipe. A partir de metas relacionadas ao nível de mão-de-obra, o gestor realiza anualmente o planejamento mensal de funcionários e acompanha a sua concretização.

- Recrutamento interno e externo. O gestor acompanha os anúncios internos de vagas e a inscrição de candidatos nas vagas de sua equipe. Esta função dá acesso também ao perfil dos candidatos externos, que têm acesso aos mesmos anúncios de vagas por meio do site da organização na Internet.

O Portal Personal também permite o acesso indiscriminado a informações e administração de processos de desenvolvimento e treinamento de pessoas. Além disso, disponibiliza diversos outros serviços que facilitam o acesso à informação relevante sobre a organização. Entre estes serviços, destacamos:

- Cursos. Em uma seção dedicada a treinamento e desenvolvimento, cursos regulares são oferecidos, em páginas que trazem detalhes como cronograma, situação da próxima turma e inscrição eletrônica.

- Cálculo de salários. Devido à complexidade do sistema trabalhista alemão, o funcionário pode usar uma calculadora que, a partir de seus parâmetros de trabalho, calcula estimativas de rendimento. 
. Classificados. Serviços de classificados de apartamentos na região. Este serviço foi uma solução encontrada para minimizar problemas específicos dos indivíduos na organização.

. Cálculo de férias. Serviço de cálculo e previsão de rendimentos associados às férias, nas diversas opções possíveis dentro da lei alemã.

Os profissionais da área de RH também possuem acesso a diversos serviços e ferramentas que se relacionam aos processos de gestão de pessoas. A página do RH dá acesso às funções que possibilitam a realização de tarefas sob a responsabilidade da área. Entre estas funções, destacamos:

- Recrutamento interno e externo. A área de RH também acompanha os anúncios internos de vagas e a inscrição de candidatos internos e externos às vagas de sua equipe.

- Mercado de trabalho. Aárea de RH dispõe de uma ferramenta que possibilita que seus analistas encontrem determinadas pessoas com certas capacidades na organização. A partir de um perfil profissional, são encontradas as pessoas que mais se encaixam nele.

- Administração de benefícios executivos. A área de RH possui uma ferramenta que a permite administrar eletronicamente diversos benefícios de seus executivos.

A implementação do sistema de RH auto-atendimento teve diversas conseqüências. A descentralização dos procedimentos de operação dos sistemas de gestão de pessoas permitiu que se colocasse em prática a nova filosofia da alta gerência, segundo a qual estes processos devem ser responsabilidade dos gestores. A implementação da TI permitiu também a transformação dos fluxos de atividades relacionados a esses processos, levando à eliminação de etapas desnecessárias na circulação das informações.

“Todo o ano os funcionários recebem notas por seu desempenho, que influenciam em seu salário variável. Antigamente, os líderes preenchiam formulários com estas notas, de acordo com os critérios da empresa. Então, enviavam os formulários para a área de RH, cujos analistas eram responsáveis pela digitação no sistema. Atualmente, todo fim de ano os próprios líderes entram em nosso sistema e digitam as notas, poupandonos desse trabalho, e tendo uma visão quase imediata das conseqüências de suas decisões".

A informatização dos diversos sistemas de gestão de pessoas permitiu a 
democratização e disseminação das informações sobre estes processos e a diminuição do poder da área de RH no contexto da organização. Essas mudanças levaram a um aumento da qualidade das respostas às demandas relacionadas às questões de pessoal. Como destacou um supervisor de RH:

“A área de RH perdeu poder com a descentralização de processos e informações. Não mais concentramos todas as informações necessárias. A área de RH pode ter todas as informações em sua mesa, ou pode falar, 'não queremos isso', damos todas as informações que vocês precisam e os executivos não precisam perguntar a todo o momento, mas eles podem olhar. Os sistemas tornam os executivos da fábrica mais independentes do RH e as respostas a suas solicitações são mais rápidas”.

Na medida em que o RH deixa de ser o intermediário entre chefes e subordinados por meio da informatização dos processos, o sistema organizacional passa a ter um nível maior de conhecimento sobre as práticas de gestão de pessoas. A democratização das informações e as novas ferramentas de gestão de pessoas tiveram diversas conseqüências no que diz respeito ao relacionamento entre chefes e subordinados: o menor poder vertical e a maior politização e responsabilidade nos relacionamentos. Um perfil mais qualificado e crítico de funcionários era estimulado por meio destas modificações. Os indivíduos passaram a negociar com sua chefia os interesses pessoais e organizacionais, na busca de melhores soluções para questões de gestão de pessoas. Um gestor descreveu assim essa transformação:

“Antigamente, executivos da área técnica como eu se preocupavam exclusivamente com questões técnicas relacionadas ao núcleo de nossa responsabilidade. Era normalmente um relacionamento entre especialistas na área. Atualmente, (...) assumimos mais responsabilidades, gastamos mais tempo lidando com questões de relacionamento humano, questões mais subjetivas que influenciam o andamento de nosso trabalho. (...) Nós somos responsáveis pela gestão das pessoas em nossa equipe. Neste cenário, a área de RH tem a responsabilidade de dar suporte, com knowhow e processos estruturados”.

A informatização dos processos de gestão de pessoas permitiu ainda a geração de um fluxo de informações que transformou a natureza das atividades desempenhadas por todos os analistas de RH, agora reorganizados nas equipes especialistas e no PDC. A informatização transformou as atividades dos analistas generalistas do PDC, que passaram a desempenhar atividades mais analíticas e consultivas. Os analistas especialistas, por sua vez, se beneficiaram do novo fluxo de informações e das novas ferramentas de trabalho viabilizadas pela TI na medida 
em que se vêem hoje diante da oportunidade de desenvolver serviços e implementar políticas antes impossíveis. Como afirmaram um analista generalista e um analista especialista:

"Por exemplo, um gestor quer dar um aumento de salário a um funcionário. Antigamente eu tinha poucas ferramentas, e as que tinham eram de difícil operacionalização, para calcular o aumento ideal. Atualmente eu disponho de uma série de ferramentas, de fácil operacionalização. E esta informação vem do conhecimento que a TI te dá da situação mais geral, tanto do grupo próximo ao empregado, quanto da empresa inteira. A informação é mais completa, as decisões ganham em qualidade”.

"Pretendíamos implementar uma nova atitude nos funcionários, baseada nas amplas possibilidades de transferência horizontal, como oportunidades de desenvolvimento profissional. A inovação era transformar a área de RH em um 'headhunter' interno, que reforçasse esta cultura de transferência. A maneira que encontramos para viabilizar esta idéia foi a sua disseminação por meio de uma ampla campanha de esclarecimento e a implementação de uma poderosa ferramenta de recrutamento e seleção da unidade de Wörth, pela Intranet”.

\section{Análise do Caso: Novo Modelo de Gestão de Pessoas}

O projeto RYB.com foi uma ampla iniciativa de transformação da gestão de pessoas da unidade DaimlerChrysler de Wörth. Antes reconhecida como operacional e envolvida em processos burocráticos, a implementação do projeto permitiu a reorganização da atuação dos profissionais de RH e viabilizou novo desenho organizacional da gestão de pessoas. Isso foi possível, em virtude das profundas transformações nos elementos constitutivos do modelo: a estrutura da área de RH e os processos de gestão de pessoas, entre outros. A TI, neste caso, é parte de uma estratégia maior de transformação organizacional, já que o seu pleno aproveitamento depende de um contexto social adequado. O caso analisado é exemplo de organização que utilizou a tecnologia como ferramenta para a emergência de moderno modelo de gestão de pessoas. Vejamos com mais detalhes como isso ocorreu.

A emergência de novo modelo de gestão de pessoas na organização se tornou possível devido aos novos padrões de relacionamento entre os atores sociais. A consolidação de novas ferramentas tecnológicas permitiu a democratização das informações sobre a gestão de pessoas e o aumento do acesso aos serviços da 
área de RH. A ampliada disponibilidade de informações e as facilidades na execução de processos reforçaram as oportunidades oferecidas pela organização e estimularam os indivíduos ao seu aproveitamento. Ao permitir novos padrões de acesso à informação sobre os processos de gestão de pessoas, a informatização possibilitou mais transparência nos relacionamentos. As necessidades de informação passaram a ser mais fácil e rapidamente satisfeitas, o que permitiu maior independência dos gestores de linha e dos funcionários em suas necessidades relacionadas a estas atividades.

A informatização dos processos de gestão de pessoas e os novos padrões de acesso à informação permitiram a transformação do relacionamento entre gestores de linha e subordinados, na medida em que os novos processos de RH demandam a aproximação entre eles. A gestão de pessoas passou a ser um processo em que a interação direta de chefes e subordinados ganha contornos mais estratégicos e maior importância, o que vai ao encontro de princípios de gestão, segundo os quais essa é uma atividade que faz parte da dinâmica entre líderes e equipes. Neste novo contexto, a área de RH deixou de ser o intermediário nas negociações dos gerentes e seus subordinados no que diz respeito aos múltiplos interesses constantemente em jogo. Os novos processos requerem mais diálogo entre subordinados e chefes, que passam a gerir não somente os aspectos técnicos de seu trabalho, mas também as amplas questões de gestão de pessoas ligadas ao desenvolvimento pessoal e organizacional por meio da operacionalização dos sistemas de RH.

Estas mudanças permitiram a emergência de novos padrões orgânicos de interação social entre seus membros: o modelo político de gestão de pessoas. Estas transformações podem ser explicadas como um distanciamento do chamado modelo instrumental de gestão de pessoas, caracterizado pelo pressuposto da existência de suposta racionalidade superior na organização. Neste modelo de gestão de pessoas, a administração de recursos humanos tem a função de implantar a estratégia definida pela direção, buscando a maximização do resultado econômico e o melhor desempenho dos empregados. O modelo instrumental adota uma visão utilitarista dos indivíduos, que devem adaptar-se à organização, vista como instrumento racional de produção econômica. Dentro deste modelo, a pluralidade de interesses e visões de mundo é vista como nociva à plena implementação das estratégias.

A tecnologia e as demais inovações organizacionais implementadas pelo projeto RYB.com, necessárias para garantir o pleno aproveitamento da TI, foram fundamentais para a emergência de padrões organizacionais orgânicos. Ao estimular novos padrões de relacionamento entre os diversos atores sociais, por meio do maior acesso às informações relativas à gestão de pessoas, aumentou- 
se a emancipação dos indivíduos. Na medida em que a interação de chefes e subordinados nas equipes de trabalho ganha papel central na gestão de pessoas, a organização assume a complexidade do comportamento social e incorpora a idéia de conflito e divergência, tendo em vista os diferentes interesses dos atores organizacionais. É possível então a construção de um contexto social em que os indivíduos podem expressar mais livremente suas racionalidades. Nos processos de negociação entre os atores sociais, as decisões tendem agora a ser mais ricas e completas.

As generosas mudanças técnicas e sociais empreendidas também viabilizaram a aprendizagem de circuito duplo entre os profissionais de RH. Na medida em que a informação foi democratizada, novas ferramentas de trabalho foram disponibilizadas e os indivíduos ficaram preparados para lidar com estes novos elementos: o antigo contato intensivo para a resolução e acompanhamento de questões operacionais cedeu espaço para o suporte estratégico. A constante especulação sobre as possibilidades dos sistemas de RH auto-atendimento permite, por exemplo, a identificação de novas oportunidades na prestação de serviços para a organização. Nossas observações mostram que, neste novo contexto, os analistas do RH são liberados de atividades operacionais para se concentrarem em tarefas mais analíticas, contribuindo para a formulação e implementação da estratégia da organização por meio da definição de novas competências, seleção e desenvolvimento de novos talentos, identificação das lideranças, elaboração de planos diferenciados de remuneração e desenvolvimento de carreiras etc. Os analistas de RH desenvolvem assim atividades voltadas para a proposição de novas idéias e para a inovação nos processos de gestão de pessoas na organização.

\section{Considerações Finais: Desafios Futuros na Transição de Modelos de Gestão de Pessoas}

No Brasil, os profissionais de recursos humanos sentem atualmente grandes pressões para que transformem a maneira como se organizam e atuam no contexto organizacional. Pesquisas sobre o contexto e atuação do RH no Brasil justificam estas pressões, ao indicar uma importante fase de transição pela qual a área passa atualmente, de uma atuação predominantemente operacional para modelos mais modernos de gestão de pessoas. Na busca de nova postura da área de RH, a tecnologia de informação pode ser considerada uma ferramenta de reconfiguração dos elementos constitutivos do modelo de gestão, viabilizando novas estratégias de gestão de pessoas; entretanto aproveitar todo o potencial da tecnologia implica a sua implementação segundo 
a lógica da informatização, o que requer normalmente inovações organizacionais na direção de padrões orgânicos de organização, o que faz com que estas mudanças sejam caracterizadas por grandes riscos e dificuldades de concretização.

No caso estudado, a organização viabilizou a emergência do modelo político de gestão de pessoas, ao implementar ampla estratégia de informatização dos processos de RH. Na realidade, para viabilizar nova estratégia de gestão de pessoas, pode-se dizer que a implementação da tecnologia de informação interagiu de maneira fundamental com outros aspectos organizacionais para a emergência deste novo sistema social. De fato, tratou-se de um movimento complexo em que diversos conceitos são inter-relacionados. Ao mesmo tempo que a implementação da tecnologia democratizou a informação, ela viabilizou a emergência do modelo político de gestão de pessoas, que é precondição para formas orgânicas de organização, nas quais a nova informação é mais bem aproveitada para a aprendizagem organizacional.

Entretanto, apesar da emergência do modelo político de gestão de pessoas na organização, não se pode dizer que a aprendizagem acontece naturalmente, na medida em que é criado ambiente favorável a ela e são dadas ferramentas tecnológicas para facilitá-la (ARGYRIS; SCHÖN, 1978). Ao considerarmos as equipes de trabalho na organização estudada, pode-se dizer que a democratização das informações permitiu que os indivíduos construíssem o contexto necessário ao desenvolvimento de uma inserção autônoma e ativa, necessária à aprendizagem; entretanto a aprendizagem acontecerá na organização na medida em que o sistema social consolide novas competências, formas de gestão e comportamentos que a operacionalizem. A gestão de pessoas, portanto, precisa ir além da criação de ambiente propício à aprendizagem, pois deve viabilizar mecanismos que a operacionalizem efetivamente. Para que se investigue com mais profundidade o envolvimento dos indivíduos no processo de formulação estratégica, deve-se verificar a implementação efetiva destes mecanismos em toda a organização, o que deve ser o objetivo de futuras pesquisas.

Ao investigarmos a construção de uma dinâmica organizacional caracterizada pela aprendizagem, algumas variáveis mostraram-se especialmente relevantes no que diz respeito ao futuro deste processo. A informatização e a reorganização da gestão de pessoas permitiram que os profissionais de RH passassem a executar outras funções no contexto organizacional. As antigas funções operacionais, que demandavam grande quantidade de recursos e tempo dos profissionais, deixaram de estar no centro das responsabilidades da área, e foram substituídas pelas preocupações com questões mais estratégicas. Neste contexto, a área tem suas responsabilidades 
aumentadas já que, além de todas as funções e atividades que desempenhava, deve fazer mais. O desafio é fazer bem o que se fez até hoje e o que se deve começar a fazer; mas as novas funções do RH requerem a capacitação dos seus profissionais para a execução de atividades especializadas, cujo papel principal é trazer conhecimento. É necessário, portanto, que eles estejam à altura dessas novas responsabilidades. Por se concentrarem historicamente em atividades consideradas operacionais, podemos argumentar que estes profissionais ainda devem preocupar-se com o preparo teórico que embasa a utilização das ferramentas práticas. Pesquisas mostram que os profissionais de RH estruturam suas ações a partir de conceitos baseados em mitos, crenças e intuição, conceitos estes muito distantes das conclusões científicas sobre temas relevantes à gestão de pessoas (RYNES; COLBERT; BROWN, 2002). O aumento da sua capacitação é essencial para que os profissionais exerçam plenamente todas as novas funções atribuídas à área.

A questão da descentralização da gestão de pessoas para os gerentes de linha também deve receber atenção especial. Os gerentes de linha assumem novo e importante papel, cujo estilo de liderança e envolvimento com a dinâmica social dos grupos passam a ser dois componentes importantes do novo modelo de gestão de pessoas. A atuação dos gerentes de linha deve refletir os pressupostos básicos do modelo de gestão de forma a facilitar a construção das novas dinâmicas. De posse da nova informação sobre a gestão de seus subordinados, os gerentes de linha devem assumir o papel de árbitros entre os múltiplos interesses de suas equipes no processo de desenvolvimento organizacional. Além de inviabilizar a aprendizagem, gerentes de linha imersos nos novos contextos informatizados, mas que mantêm perfis de gestão desatualizados, podem causar percepções contraditórias nos membros da equipe e gerar estresse e frustração na organização (VASCONCELOS; VASCONCELOS, 2004).

Vemos que a consolidação de novos modelos de gestão de pessoas, caracterizados pela aprendizagem em circuito duplo, é processo contínuo; não se trata de ação gerencial com fim determinado no tempo, mas de jornada permanente. A DaimlerChrysler mostra ter desempenhado bem estes passos iniciais. Pesquisas futuras poderão verificar se foram criados os fundamentos duradouros de uma Learning Organization ou não.

Artigo recebido em 15.08.2003. Aprovado em 10.03.2004. 


\section{Referências Bibliográficas}

ARGYRIS, C.

On organizational learning.

Cambridge, MA: Blackwell. 1992.

ARGYRIS, C.E;

SCHÖN, D.

Organizational learning: a theory of action perspective. Reading, Mass.:

Addison-Wesley, 1978.

\section{ALBERTIN,A.}

Comércio eletrônico: benefícios e aspectos de sua aplicação. Revista de Administração de Empresas, São Paulo, Volume 38, n.1, p. 52-63, Jan./ Mar. 1998.

\section{BERKLEY, J.;}

NOHRIA, N.

The virtual organization. In: HECKSCHER, C., DONNELLON, A., The post bureaucratic organization. London: Sage Publications, 1994. Pág. 108-128, cap. 5.

\section{BRABET, J.}

Repenser la gestion des ressources humaines. Paris: Economica, 1993.

BURNS, T.;

STALKER, G.

Mechanistic and organic systems. In: SHAFRITZ, J.; OTT, J. Classics of organizational theory. $5^{a}$ edição, Belmont: Wadsworth Group, 2001.Pág. 201-205, cap. 20.

\section{CASTELLS, $M$.}

A sociedade em rede. São Paulo: Paz e Terra, 1999.
FISCHER, A.L.

A constituição do modelo competitivo de gestão de pessoas no brasil - um estudo sobre as empresas consideradas exemplares, 1998. Tese de Doutorado. Faculdade de Economia, Administração e Contabilidade da Universidade de São Paulo, São Paulo.

Um resgate conceitual e histórico dos modelos de gestão de pessoas, In: FLEURY, M. (org.), As pessoas na organização. São Paulo: Editora Gente, 2002. Pág. 11-33, cap. 1.

\section{FISCHER, A. L.;}

ALBUQUERQUE, L.

Tendências que orientam as decisões dos formadores de opinião em gestão de pessoas no Brasil. In: ENCONTRO ANUAL DA ANPAD, 25., 2001, Campinas. Anais... Campinas: 2001.

KLING R.

The centrality of organizations in the computerization of society, In: KLING, R. Computerization and controversy: value conflicts and social choices. $2^{\mathrm{a}}$ edição. San Diego: Academic Press, 1996. Pág. 108-132.

\section{LACOMBE, B.;}

TONELLI, $\mathrm{M}$.

O discurso e a prática: o que nos dizem os especialistas e o que nos mostram as práticas das empresas sobre os modelos de gestão de recursos humanos. In: ENCONTRO ANUAL DAANPAD, 25, 2000, Florianópolis. Anais... Florianópolis: 2000. 
LAWLER III, E.;

MOHRMAN, A.

Administração de recursos humanos: construindo uma parceria estratégica. In: GALBRAITH, J.; LAWLER III, E. Organizando para competir no futuro. São Paulo: Makron Books, 1995.

\section{LETART, J.}

A look at virtual HR: how far behind am I? HRMagazine, Alexandria, Jun 1998. Disponível em: <http:// proquest.umi.com/pqdweb>. Acesso em: 18 de Mar. 2002.

\section{MASCARENHAS, A.}

Tecnologia da informação e gestão de pessoas - o valor da TI na transição da área de RH. 2003205 páginas. Dissertação (Mestrado em Administração de Empresas) - Fundação Getulio Vargas - FGV-EAESP. São Paulo.

\section{MCCORMICK, S.}

The virtual HR organization, Management Accounting, v.. 80, ISS: 4, p. 48-51, Out. 1998. Disponível em: <http://proquest.umi.com/pqdweb> Acesso em: 18 de Mar. 2002.

\section{MORTON, M.}

How information technologies can transform organizations, In: KLING, R. Computerization and controversy: value conflicts and social choices. $2^{\mathrm{a}}$ edição. San Diego: Academic Press, 1996. Pág. 148-160.

\section{ORLIKOWSKI, W.}

Learning from notes: organizational issues in groupware implementation, In: KLING, R. Computerization and controversy: value conflicts and social choices. $2^{\mathrm{a}}$ edição. San Diego: Academic Press, 1996. Pág. 173-189.

RYNES, S.;

COLBERT,A.

BROWN, K.

HR Professional beliefs about effective human resource practices, correspondence between research and practice. Human Resource Management, vol. 41, n.2, summer 2002, p.149-174.

\section{SCOTT, R.}

Organizations: Rational, Natural and open systems, $2^{a}$ edição. Englewood Cliffs: Prentice-Hall, 1992.

SIMON, $\mathrm{H}$.

A behavioral model of rational choice. Quarterly Journal of Economics, Cambridge, MA, v.69, p. 99-118, Fev. 1955.

\section{WALTON, R.}

Tecnologia da informação: o uso de TI pelas empresas que obtêm vantagem competitiva. São Paulo: Editora Atlas, 1994.

\section{TEUKE, M.}

Pathways to performance, Chief Executive, Feb. 2001, p. 14. Disponível em: <http://proquest.umi.com/ pqdweb> Acesso em: 18 de Mar.2002.

ULRICH, D. (org.)

Recursos humanos estratégicos novas perspectivas para os profissionais de RH. São Paulo: Editora Futura, 2000. 
VASCONCELOS, I.;

VASCONCELOS, F.

Paradoxos organizacionais - uma visão transformacional. São Paulo:

Thomson Learning, 2004. No prelo.

Gestão de recursos humanos e identidade social: um estudo crítico, Revista de Administração de Empresas, São Paulo, v.. 42, n.1, p.6478, jan./mar.2002.

YIN, R.

Estudo de caso: planejamento e métodos. $2^{\text {a }}$ edição.Porto Alegre: Ed. Bookman, 2001.

\section{ZUBOFF, S.}

Automatizar/informatizar: as duas faces da tecnologia inteligente. Revista de Administração de Empresas, São Paulo, v. 34, n.6, Pág. 80-91. Nov./Dez. 1994.

In the age of the smart machine: the future of work and power. Nova Iorque: Basic Books, 1988. 